\title{
Put your Own Oxygen Mask Before Helping Others
}

\author{
Jitendra Mistry ${ }^{1}$ \\ Received: 15 June 2020 / Accepted: 18 June 2020 / Published online: 26 June 2020 \\ (C) Association of Surgeons of India 2020
}

The latest amendment in Hippocratic Oath was made on 14th October 2017 at Chicago in general assembly of world medical association [1]. Out of few notable changes made, there is a striking entry of a clause for doctor's own health. It reads, "I WILL ATTEND TO my own health, well-being, and abilities in order to provide care of the highest standard". Although this clause is preceded by the clause, "THE HEALTH AND WELL BEING OF MY PATIENT will be my first consideration", the amendment has given a space to the doctors.

The question comes in the mind; what has brought the change of adding doctor's health and well-being into the picture? Is it the observation that doctors themselves neglect their health [2], or is it a subconscious response of the medical fraternity for treating doctors as service providers and patients as consumers?

The Covid-19 pandemic gives a unique situation to discuss this clause in perspectives when there is health risk on either side, for patients and doctors. This is especially important for smaller hospitals and nursing homes which give treatment to non-Covid patients. These smaller hospitals are the cornerstone of healthcare in India, but it is not feasible to take the highest level of precautions at this level of facilities. Keeping these hospitals close would be a disservice to patients, and keeping them open carries a definitive risk to doctors and health workers. In case of spread through hospitals, there is a risk of doctors being blamed by public and media, and losing the reputation in seconds. If you are a surgeon, in India until recently pre-operative test for Covid was not approved. Surgery carries a significant risk of spread of Covid infection, even in latent period or asymptomatic carriers. Universal precautions in form of PPE (personal protective equipment) are

The publication has not been published before and is not under consideration elsewhere.

Jitendra Mistry

jitlap@gmail.com

1 Mission Gastrocare, an Institute of Gastroenterology, Liver Pancreas \& GI Cancer Sciences, Vadodara, Gujarat 390007, India being advised. There is a definitive scarcity of PPE, ideal PPE is even a bigger problem. Majority hospitals use PPE in operation theatres but not in wards; its financial viability is doubtful. Is it alright to use universal precautions only in operation theatre, when the disease is spread by respiratory route? There is no enough data to comment about risk involved in laparoscopic surgery which has its own benefits, but there is a perceived higher risk of aerosol formation and infection transmission $[3,4]$. Offering open surgery to these patients, whether is a fair decision or not is another question to be answered.

At the present, we have more questions than answers. The bottom line is how to balance between the health of a patient and health of a doctor (as per revised Hippocratic Oath). What comes in my mind, the frequently spoken line by crew while safety demonstration in flight; "put your own oxygen mask before helping others", because if more and more doctors go into quarantine, ultimately, it is a bigger loss to the society.

\section{Compliance with Ethical Standards}

Conflict of Interest The author declares that he has no conflict of interest.

\section{References}

1. Amended by the 68 WMA General Assembly, Chicago, United States, October 2017

2. Wiskar K (2012) BCMJ 54(8):419-423

3. Alp E, Bijl D, Bleichrodt RP, Hansson B (2006) Voss a surgical smoke and infection control. J Hosp Infect 62(1):1-5

4. Choi SH, Kwon TG, Chung SK, Kim TH (2014) Surgical smoke may be a biohazard to surgeons performing laparoscopic surgery. Surg Endosc 28(8):2374-2380

Publisher's Note Springer Nature remains neutral with regard to jurisdictional claims in published maps and institutional affiliations. 